\title{
A Case for Returning to Multiplex Families for Further Understanding the Heritability of Schizophrenia: A Psychiatrist's Perspective
}

\author{
Lynn E. DeLisi \\ VA Boston Healthcare System, Brockton, Mass., and Harvard Medical School, Boston, Mass., USA
}

\section{Key Words}

Schizophrenia $\cdot$ Heritability $\cdot$ Mutations $\cdot$ Families

\begin{abstract}
The genetic mechanism for schizophrenia still remains unknown despite decades of research. A tremendous amount of investigator time and effort has gone into ascertainment of clinical samples for genetic studies over the years. Most recently, a large international effort of unprecedented collaboration has occurred to combine data worldwide in pursuit of uncovering the relevant genetic risk factors. However, in the process, the use of multiplex families to understand the genetics has waned, and it has been presumed that large resources of unrelated patients and controls are more efficient to find risk alleles than families. This commentary is a call to return to the use of this largely abandoned resource for further understanding the underlying biological mechanism of this serious mental illness.

๑) 2016 S. Karger AG, Basel
\end{abstract}

Several previous large family studies of schizophrenia have shown that schizophrenia clusters in families more often than would be expected by its prevalence in the general unrelated population [1]. Even more relevant is the fact that twin studies show that monozygotic twins are significantly more concordant for illness than dizygotic twins [2], and adoption studies show that the biological, and not adoptive, relatives of people with schizophrenia are at increased risk for the disorder [3]. These studies, particularly on twins, have led to early heritability estimates for schizophrenia to be approximately 0.80 [4], although more recent calculations based on larger epidemiological studies suggest that heritability may be lower at about 0.67 [5]. Nevertheless, this is sufficient to warrant a focus on attempting to find a genetic mechanism or mechanisms for the disorder.

In the early 1980s, technology in the field of molecular genetics grew exponentially, and thus a new era began that enabled the examination of individual variation in increasing numbers of polymorphic DNA markers. During that time, a few pioneering psychiatric researchers began identifying and examining families that had multiple affected individuals, taking blood samples for isolating DNA, and also storing lymphoblastoid cell lines on individuals to have continual supplies of DNA for future studies (e.g. [6]). Polymorphisms in many 'candidate' genes were examined in the 1980s; few, if any, stood the test of time. The principle was that if there was a major gene locus conferring risk for schizophrenia and if the whole genome could be systematically screened, then

\section{KARGER}

E-Mail karger@karger.com www.karger.com/mnp
(C) 2016 S. Karger AG, Base

2296-9209/16/0021-0015\$39.50/0
Lynn E. DeLisi, MD

VA Boston Healthcare System 940 Belmont Street

Brockton, MA 02301 (USA)

E-Mail Lynn.DeLisi@VA.gov 
linkage studies using multiplex families would surely uncover its chromosomal location and ultimately lead to the gene, as had begun to happen for other autosomal dominant or recessive illnesses. Toward this goal, an early collaborative group, from the European Science Foundation (ESF), was formed and brought European investigators together to share families and methods of ascertainment. Shortly afterward, a similar one was established at the National Institute of Mental Health (NIMH) with 3 collaborative centers providing a widely available set of family DNA samples with corresponding diagnoses. There was then a large number of individual investigator-led linkage studies published in the 1990s and early 2000s using restriction fragment length polymorphism and microsatellite markers (usually about 3-400) spread throughout the genome; but these ultimately led to many findings on different chromosomes that on the surface appeared inconsistent across independent cohorts, although taken together in a meta-analysis, they yielded some suggestive regions that could have been locations for some rare mutations segregating in families [7]. The consensus of the field at that time was that multiple genes of smaller effect must be involved and that linkage studies were not likely to be a fruitful way forward, at least when focusing on a 'schizophrenia' phenotype.

About the time the above mentioned meta-analysis was reported, molecular genetics laboratory methods had advanced further, from the coverage of an average of 3-400 markers in the form of single nucleotide polymorphisms spanning the genome to 1 million on small commercial chips. With the development of HapMap along with high throughput genotyping platforms by commercial companies, such as the Affy chip and the Illumina Optical Array, it was felt that markers were now so close together that a genome-wide association study (GWAS) could uncover the risk alleles far more efficiently, and thus the enthusiasm for finding more multiplex families waned.

In addition, many investigators began reasoning that the 'endophenotype', a factor intermediate along the pathway from gene to clinical syndrome, was more likely to be what was inherited and, thus, biological and cognitive studies were proposed as 'endophenotypes' that are still being pursued [8]. However, to date no clear 'endophenotype' has emerged, nor been very useful for linkage studies any more so than diagnosis itself.

During this time of growth in the field of molecular genetics, the International Society of Psychiatric Genetics (ISPG; www.ISPG.net) was established (in 1992) to coalesce researchers in this field and to share new data and ways to collaborate. It was during one of the annual meetings of the ISPG in Boston, 2005, that a closing panel session discussing future directions in the field called for researchers to contribute samples of patients and controls to a repository for combining them into the largest-ever GWAS that could be performed (reviewed in [9]). Concurrent with discussions at this meeting and in the pursuit of other disease genes, it was becoming widely recognized that a GWAS with very large numbers of samples was the way to go to understand the genetics of any complex disorder likely to have many risk genes of small effect.

For schizophrenia and other psychiatric disorders, a few thousand samples were proposed that some investigators thought were unnecessarily large and unreachable, but as time went on, the need for more and more samples continued to be the focus. The NIMH partnered with private groups to develop the early GAIN collaboration for combining samples and data. This eventually became one of the precursors to the now active Psychiatric Genomics Consortium (PGC; https://www.med.unc.edu/pgc) begun in 2007 that now includes several hundreds of investigators worldwide. Slowly, GWAS's were published from this set of collaborations: first with 3,322 patients and 3,587 controls [10], to 13,833 patients and 18,310 controls [11], and most recently to 36,989 patients and 113,075 controls [12]. Initially, first with only a few thousand samples, a very small number of risk genes were found, but as the numbers approached several thousands, clear findings and more risk loci emerged. It is understood that the PGC intends to even proceed further to at least 100,000 patients and even more controls. They have also widened their collaborative arms to include several other diagnostic categories. What has come out of these analyses so far with respect to schizophrenia is that, as the sample increases in size, so does the number of common alleles (now at 108 loci [12]) reported to be of significant risk, albeit at a very modest elevation in risk. The results were only achieved with success so far because of the talented PGC leadership and the many investigators worldwide willing to readily contribute their samples and data.

If there are over 100 common risk alleles for schizophrenia and multiplex families have them as well, it might be expected that within multiplex families, affected individuals have inherited significantly greater numbers of these than nonaffected members, either the same or different ones. However, if these risk alleles are not relevant to multiplex families, this would also be important information. The PGC has now, based on their findings, calculated a polygenic risk score (PRS) that can quantitate
16

Mol Neuropsychiatry 2016;2:15-19 DOI: $10.1159 / 000442820$
DeLisi 
one's risk for schizophrenia. There are several ways in which the PRS can be calculated, but the simplest is certainly to add up the presence of all risk alleles for each individual that in the very large dataset of approximately 100,000 individuals were shown to have a significant genome-wide association with schizophrenia (a maximum of 108 loci). This score still only predicts a small portion of the variance in risk and, thus, many people with a high PRS are unlikely to have the illness, and its specificity for schizophrenia is also low [13]. It would certainly be interesting to calculate the PRS for all affected members in multiplex families. If it appears high in a cohort of such families, this would implicate that multiplex families are derived from having had inherited an unusually large number of common risk alleles. On the other hand, if it is not any more elevated than in the population as a whole, other mechanisms are likely to explain the large number of affecteds in a family. While common risk alleles are clearly important for risk for schizophrenia, an explanation is still needed for the so-called 'missing heritability', and this could be the additional presence of rare mutations that can lead to illness [14], such as those that may be found in multiplex families.

In parallel to GWAS, there were reports of discoveries of copy number variants (CNVs) in the genome that appeared increased in populations of patients with schizophrenia, suggesting that in addition to common polymorphisms of modest effect, there may also be some rare mutations of more moderate effect $[15,16]$. After uncovering several CNVs associated with schizophrenia [17], McClellan et al. [18] proposed the alternate hypothesis that multiple rare inherited or spontaneously formed mutations, unique to individual families, underlie the biological basis for schizophrenia. However, given that many CNVs found among patients with schizophrenia appear to be de novo mutations [19], CNVs and other newly recognized de novo exonic mutations [20-22] may not explain the high heritability estimates, nor the high prevalence of illness, particularly in the observed multiplex families. Based on the PGC's large GWAS dataset, it has now been calculated that as much as $18 \%$ of the risk for schizophrenia can be explained by multiple genes of small effect using the PRS [communications in multiple PGC presentations at the latest World Congress of Psychiatric Genetics, October 15-21, 2015]. This unpublished $18 \%$ is much higher than the previously published approximately $7 \%$ [12]. However, neither the presence of de novo mutations nor multiple common risk alleles negate the need to also examine multiplex families, as it is likely that the heritability of schizophrenia is not made up of any one

Multiplex Families and the Heritability of Schizophrenia mechanism. Certainly, a portion of the heritability could still be explained by rare inherited moderately penetrant alleles that are unique to individual families and may not even be in the same gene across families. Taken together, patterns may emerge that ultimately will uncover biologic pathways underlying the illness.

It is difficult to know how many multiplex families will be needed to clarify the underlying biology. In general, one would predict, based on an approximately $10 \%$ risk to relatives, that in families of probands with schizophrenia (if the family is extended to any degree relative) with a minimum of 5 members, there may be as many as $40 \%$ of them that have another relative with schizophrenia [23]. Thus, a study design that would lead to advances using multiplex families would ideally be a large epidemiological one, whereby whole populations are surveyed for schizophrenia and then their families ascertained for presence of other affected members. However, multiplex families have always been more difficult to ascertain for research studies than the statistics would suggest and are thus thought to be too rare to be relevant. The clinical manifestations of the illness of schizophrenia itselflead to reduced fecundity, smaller family size, general family discord and separation, and to considerable increase in suicides of affected individuals. Multiplex families may actually be much more common than assumed, but blood samples are not readily available from complete families for research for the reasons stated. In rare instances, such as in isolated geographical regions where very large sibships occur, families with multiply ill members can more easily be found and ascertained for such studies (e.g. [24]).

There are other reasons why families can be extremely valuable. For example, they are much more suitable than cohorts of unrelated individuals for examining the effects of shared environments, assortative mating, and parent of origin effects. They may particularly be advantageous for assessing dominant effects (interaction between different alleles at the same locus), and they may be useful for the detection of epistasis (gene-gene interaction), given that penetrance may be high in such families [25].

Ultimately, the need for multiplex families will likely be re-questioned. Why do they exist at all still is an open question, and the possibility that they may be carrying dominant or recessive highly penetrant mutations in a relevant gene cannot be ruled out. While rare missense mutations are found in unrelated patients, it cannot be shown that these are relevant in any way to the illness and not just a coincidental finding without examining them within families to determine whether they segregate with 
illness. If other members have the mutation, and if it segregates with illness within that family, then the likelihood that the mutation is pathogenic and worth further pursuit to understand its underlying biology will be high. Thus far, despite specific CNVs being found to be associated with schizophrenia and other psychiatric disorders, and common risk alleles being reported, it is unknown whether these have any value for predicting risk for development of illness in other family members. Nor is it known whether the mutations appear simply by chance and may be neither sufficient nor necessary to cause illness. Although possibly an alternative approach, it will take very large numbers of unrelated individual samples to perform a rare-variant association study, such as described by Zuk et al. [14]. Ott et al. [26] urge the field not to abandon 'linkage' as a tool for finding candidate risk genes and in a recent review give new methods for linkage analyses with whole-genome sequencing data on families. This may encourage more investigators to reexamine large families previously abandoned. They have not yet, however, designed a package that could both analyze linkage and association together with these data.

This commentary is only arguing that returning to multiplex families would be important, particularly when searching for rare variants; but this is not to say that it is the only way forward. For example, as mentioned above, Zuk et al. [14] show that very large groups of unrelated patients (in the order of 25,000 ) can obtain statistical evidence for the relevance of rare variants associated with disease without examining families. Nevertheless, some preliminary evidence already exists that multiplex families may harbor rare unique mutations that segregate with illness and implicate important underlying biological pathways $[27,28]$.

In summary, the discussion to be pursued in coming months is where to focus beyond GWAS. It is proposed here that a return to multiplex families to obtain both DNA and comprehensive clinical information may be an important, but currently overlooked, way in which the genetic mechanisms for schizophrenia will be understood. This is in essence returning to where the field began, examining the patterns of illness in families of schizophrenia probands, as was done in the large early family studies, but with new technology, and even using them as a resource to study the underlying illness biology by creating induced pluripotent stem cell lines. Thus, the differences that make this return to such families imperative are the advancements that have since taken place in molecular neuropsychiatry.

\section{Disclosure Statement}

The author is funded to perform family research studies by Amgen, Inc. She has no other conflicts of interest to disclose.

\section{References}

1 Gottesman II, Shields J: A critical review of recent adoption, twin and family studies of schizophrenia: behavioral genetics perspectives. Schizophr Bull 1976;2:360-401.

2 Shields J, Gottesman II: Cross-national diagnosis of schizophrenia in twins. The heritability and specificity of schizophrenia. Arch Gen Psychiatry 1972;27:725-730.

3 Kety SS, Wender PH, Jacobsen B, Ingraham LJ, Jansson L, Faber B, Kinney DK: Mental illness in the biological and adoptive relatives of schizophrenic adoptees: replication of the Copenhagen study in the rest of Denmark. Arch Gen Psychiatry 1994;51:442-455.

4 McGuffin P, Farmer AE, Gottesman II, Murray RM, Reveley AM: Twin concordance for operationally defined schizophrenia. Confirmation of familiality and heritability. Arch Gen Psychiatry 1984;41:541-545.

5 Wray NR, Gottesman II: Using summary data from the Danish national registers to estimate heritabilities for schizophrenia, bipolar disorder, and major depressive disorder. Front Genet 2012;3:118.
6 DeLisi LE, Goldin LR, Maxwell ME, Kazuba DM, Gershon ES: Clinical features of illness in siblings with schizophrenia or schizoaffective disorder. Arch Gen Psychiatry 1987;44:891896.

7 Ng MY, Levinson DF, Faraone SV, et al: Metaanalysis of 32 genome-wide linkage studies of schizophrenia. Mol Psychiatry 2009;14:774785.

8 Braff DL: The importance of endophenotypes in schizophrenia research. Schizophr Res 2015; 163:1-8.

9 DeLisi LE, Faraone SV: When is a 'positive' association truly a 'positive' in psychiatric genetics? A commentary based on issues debated at the World Congress of Psychiatric Genetics, Boston, October 12-18, 2005. Am J Med Genet B Neuropsychiatr Genet 2006; 141B:319-322.

10 International Schizophrenia Consortium, Purcell SM, Wray NR, Stone JL, Visscher PM, O’Donovan MC, Sullivan PF, Sklar P: Common polygenic variation contributes to risk of schizophrenia and bipolar disorder. Nature 2009;460:748-752.
11 Ripke S, O’Dushlaine C, Chambert K, et al; Multicenter Genetic Studies of Schizophrenia Consortium, Levinson DF, Gejman PV, Kendler KS, et al; Psychosis Endophenotypes International Consortium, Arranz MJ, Bakker S, Bender S, et al; Wellcome Trust Case Control Consortium 2, Donnelly P, Barroso I, Blackwell JM, et al: Genome-wide association analysis identifies 13 new risk loci for schizophrenia. Nat Genet 2013;45:1150-1159.

12 Schizophrenia Working Group of the Psychiatric Genomics Consortium: Biological insights from 108 schizophrenia-associated genetic loci. Nature 2014;511:421-427.

13 Agerbo E, Sullivan PF, Vilhjálmsson BJ, Pedersen CB, Mors O, Børglum AD, Hougaard DM, Hollegaard MV, Meier S, Mattheisen M, Ripke S, Wray NR, Mortensen PB: Polygenic risk score, parental socioeconomic status, family history of psychiatric disorders, and the risk for schizophrenia: a Danish population-based study and meta-analysis. JAMA Psychiatry 2015;72:635-641. 
14 Zuk O, Schaffner SF, Samocha K, Do R, Hechter E, Kathiresan S, Daly MJ, Neal BM, Sunyaev SR, Lander ES: Searching for missing heritability: designing rare variant association studies. Proc Natl Acad Sci USA 2014; 111:E455-E464.

15 Malhotra D, McCarthy S, Michaelson JJ, et al: High frequencies of de novo CNVs in bipolar disorder and schizophrenia. Neuron 2011;72: 951-963.

16 Vacic V, McCarthy S, Malhotra D, et al: Duplications of the neuropeptide receptor gene VIPR2 confer significant risk for schizophrenia. Nature 2011;471:499-503, erratum in Nature 2011;474:114.

17 Walsh T, McClellan JM, McCarthy SE, et al: Rare structural variants disrupt multiple genes in neurodevelopmental pathways in schizophrenia. Science 2008;320:539-543.

18 McClellan JM, Susser E, King MC: Schizophrenia: a common disease caused by multiple rare alleles. Br J Psychiatry 2007;190:194199.

19 Georgieva L, Rees E, Moran JL, Chambert KD, Milanova V, Craddock N, Purcell S, Sklar P, McCarroll S, Holmans P, O’Donovan MC, Owen MJ, Kirov G: De novo CNVs in bipolar affective disorder and schizophrenia. Hum Mol Genet 2014;23:6677-6683.

$20 \mathrm{Ku}$ CS, Tan EK, Cooper DN: From the periphery to centre stage: de novo single nucleotide variants play a key role in human genetic disease. J Med Genet 2013;50:203-211.

21 Rees E, Kirov G, Walters JT, et al; Taiwanese Trios Exome Sequencing Consortium, Neale BM, Palotie A, Sklar P, et al: Analysis of exome sequence in 604 trios for recessive genotypes in schizophrenia. Transl Psychiatry 2015; 5:e607.

22 Kranz TM, Harroch S, Manor O, Lichtenberg P, Friedlander Y, Seandel M, Harkavy-Friedman J, Walsh-Messinger J, Dolgalev I, Heguy A, Chao MV, Malaspina D: De novo mutations from sporadic schizophrenia cases highlight important signaling genes in an independent sample. Schizophr Res 2015;166: 119-124.

23 Farmer A, McGuffin P, Gottesman II: Problems and pitfalls of the family history positive and negative dichotomy: response to Dalen. Schizophr Bull 1990;16:367-370.

24 DeLisi L, Mesen A, Roderiguez C, Bertheau A, LaPrade B, Llach M, Riondet S, Razi K: Clinical characteristics of schizophrenia in multi- ply affected Spanish origin families from Costa Rica. Psychiatr Genet 2001;11:145-152.

25 An P, Mukherjee O, Chanda P, Yao L, Engelman CD, Huang C-H, Zheng T, Kovac IP, Dubé M-P, Liang X, Li J, de Andrade M, Culverhouse R, Malzahn D, Manning AK, Clarke GM, Jung J, Province MA: The challenge of detecting epistasis $(\mathrm{G} \times \mathrm{G}$ interactions): $\mathrm{Ge}$ netic Analysis Workshop 16. Genet Epidemiol 2009;33:S58-S67.

26 Ott J, Wang J, Suzanne M: Leal SM: Genetic linkage analysis in the age of whole-genome sequencing. Nat Rev Genet 2015;16:275-284

27 Timms AE, Dorschner MO, Wechsler J, Choi KY, Kirkwood R, Girirajan S, Baker C, Eichler EE, Korvatska O, Roche KW, Horwitz MS, Tsuang DW: Support for the N-methyl-D-aspartate receptor hypofunction hypothesis of schizophrenia from exome sequencing in multiplex families. JAMA Psychiatry 2013;70: 582-590.

28 Homann O, Misura K, Nelson P, McDonough $S$, DeLisi LE: DNA sequencing in multiplex families with schizophrenia reveal mutations in the SHANK2, SMARA1, TEAD1 and TGMS6 genes segregating with illness within pedigrees. In press. 